\title{
Subcutaneous radiofrequency: prospective pilot study on safety and efficacy in face chrono-ageing treatment
}

\begin{abstract}
Objective: to evaluate the efficacy, safety and tolerance of the face aging treatment using subcutaneous radiofrequency in patients with mild, moderate e severe ptosis of the middle face.

Material and methods: prospective data from patients treated with subcutaneous radiofrequency. Patients underwent two treatment session carried out by the same surgeon. The principal efficacy criterion was the assessment of depth reduction of the naso-labial fold and malar prominence's restoration after 3 and 6 months, the evaluation of the Global Aesthetic Improvement Scale by the patients and an outside procedure surgeon was the second criteria. Safety and tolerance were evaluated through observed side effects.
\end{abstract}

Result: A total of 30 patients, 27 women and 3 men with a mean age of 53 years underwent subcutaneous radiofrequency procedure. Depth's reduction of the naso-labial fold and malar prominence's restoration was observed in the majority of all case, associated to the patient e medical satisfaction. Transitory adverse effects, commonly for cosmetic procedure e.g erythema, edema was not observed. One patient had post procedure hematoma. No serious adverse effects such as burning or scars were reported.

Conclusion: This prospective pilot data confirmed that subcutaneous radiofrequency is a safe and effective in improvement in skin laxity. Patients' satisfaction was high. Although this treatment cannot substitute surgical procedure, it might prolong the time to the first surgical facial lift. Further confirmation investigation should be performed.
Volume 5 Issue 3 - 202I

\author{
Benedetta Fanelli,' Nicolò Scuderi² \\ 'Plastic and Reconstructive Surgery Unit,Azienda Ospedaliera \\ San Giovanni-Addolorata, Italy \\ ${ }^{2}$ Plastic and Reconstructive Surgery Unit, Sapienza Università di \\ Roma, Italy
}

Correspondence: Benedetta Fanelli, Plastic and Reconstructive Surgery Unit, Azienda Ospedaliera San GiovanniAddolorata, Italy, Email benedetta_fanelli@libero.it

Received: May 15, 2021 | Published: May 27, 2021

Keywords: facial skin laxity, endodermal radiofrequency

\section{Introduction}

Fundamental features of facial aging result from the resorption of the bone skeleton from the sliding of the volumes due to increased skin laxity. Factors predisposing laxity are divided into intrinsic, such as connective tissue disorders and extrinsic such as exposure to ultraviolet rays and cigarette smoke. ${ }^{1}$

The presence of collagen in the skin is due to the balance between its degradation and its neosynthesis, it is estimated that every year the skin loses about $1 \%$.The heating of this important skin component causes protein denaturation with loss of the natural triple helix structure. In the event that the heat does not lead to complete denaturation, crosslinks persist which are responsible for the shrinkage and thickening of the collagen. ${ }^{2,3}$

The signs of facial aging can be treated with different minimally invasive procedures ranging from fillers to restore volume loss and correct deep wrinkles, lasers, pulsed light to improve skin texture, chemodenervation with botulinum toxins for the treatment of wrinkles in the upper third of the face. ${ }^{4,5}$

In the last decades, radiofrequency has also become a useful tool for the treatment of facial aging. The radiofrequency current circulates through a closed circuit and the passage of the particles through the tissues causes heat due to the diathermy. The flow of the radiofrequency current is influenced by the percentage of water contained in the tissues, those with higher percentages such as subcutaneous fat generate heat allowing the deeper effects of the technology. ${ }^{6}$

Comes in 2002 the approval of the treatment of the periorbitary wrinkles by monopolar radio frequency (thermage) by the american FDA.

The treatment by means of diathermy, that is the generation of heat by the passage of a radiofrequency current through the tissues, causes a contraction of the dermal collagen and also stimulates the formation of new collagen by direct effect on the dermal matrix by stimulation of the fibroblasts and increased vascularity. Responses depend on the distribution and timing of exposure to high temperature..$^{2-7}$

In literature, studies using electronic microscopy show the immediate denaturation of collagen after heating with fibril contraction and thickening. ${ }^{6}$

The late inflammatory response as per wound healing is responsible for neo-collagenesis. The heating of the fibrous septae of the subcutis causes the immediate improvement of the skin contour. ${ }^{8}$

\section{Materials and methods}

This was an open trial for face chrono-ageing treated with endodermal radiofrequency ATTIVA ${ }^{\circledR} .3$ male and 27 female patients were included after obtaining informed consent. Patients with an ongoing anticoagulant treatment, implanted pacemakers or defibrillator were not included, since this is an absolute contraindication for RF 
therapy. Patients with presence of acute systemic infections and local infections such as herpes simplex or impetigo and those with open wounds in the area of treatment were excluded. Patients with genetic disorders of connective tissue, like cutis laxa, were excluded from this trial.

We used the ATTIVARF ${ }^{\circledR}$, device for capacitive and resistive diathermy, in monopolar mode, using a partially shielded $15 \mathrm{~cm}$ cannula needle and a probe transmitting the set energy in sub-dermal tissue. Monopolar systems deliver current through a single contact point with an accompanying grounding pad that serves as a low resistance path for current flow to complete the electrical circuit.

The procedure was carried out, in a lying position, on an outpatient basis, using local anesthesia at the cannula entry point. In some patients a troncular anesthesia was required in addition.

All treatments provided two entry points for the cannula with a retracting movement on the surgical lifting vectors. (Figure 1)

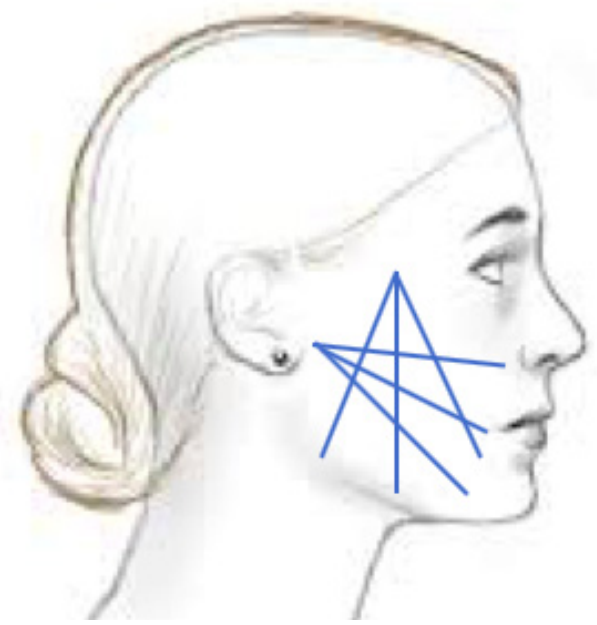

Figure I Entry point and retracting cannulas movement on the surgical lifting vectors.

All patients underwent two treatment session, at a distance of 45 days from each other, with cutaneous lift program (180 seconds) with a temperature range between 45 and 50 , performed by the same physician.

A first consultation was scheduled in order to provide the patient with all the information concerning the procedure, obtain the signed consent, and to check that there were not contraindications. During this consultation, an examination to measure the skin laxity by the Global Facial Assessment Score (GAIS) was carried out by the doctor and a patient evaluation is also required; photos were taken for reference ${ }^{17}$ (Figure 2)

A follow up consultation was planned 1 week later to evaluate side effects, 1 mouth later, 3 and 6 months later and a final control visit look place 12 mouth after the procedure to assess the treatment outcome.

The global efficacy of endodermal ATTIVA RF® was assessed through the depth reduction of the naso-labial fold and the malar prominence's restoration after 3, 6 and 12 months by the evaluation of the Global Aesthetic Improvement Scale.

A blinded score of the photos was performed by a doctor not involved in treatment. Scoring was carried by the evaluation of the Global Aesthetic Improvement Scale.
Safety and tolerance were evaluated through observed side effects.
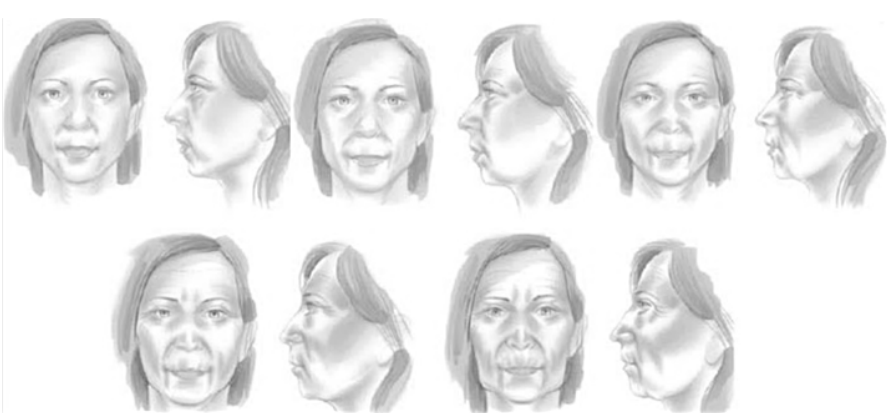

Figure 2 Global facial assessment. Grade I: Early grade of lipoatrophy characterized by a mild flattening of several facial areas, including cheek, temple, preauricular and periorbital areas; Grade 2: an intermediate stage between grades I and 3; Grade 3: typified by moderate concavity and increasing prominence of body landmarks; Grade 4: Intermediate between grade 3 and 5; Grade 5: Severe indentation of one or more facial regions and severe prominence of bony landmarks. ${ }^{17}$

\section{Results}

This prospective pilot study included 30 patients: 27 woman and 3 men, with an average age of 53. Four patients were smokers. All patients were Caucasians with photo-skin type I to III; the majority $(\mathrm{n}=13)$ had a skin type II

The procedure need only anesthesia in the cannula entry point but in two patientsa troncular anesthesia was required in addition. We did not see any adverse effect, such as burning, ecchymosis or pigmentary changes. Treatment took only 40 minutes.

Patients mainly presented face chrono-ageing with a pre-treatment average Global Facial Assessment value of 2,6.

Improvement in facial skin laxity with the reduction of the nasolabial fold and malar prominence's restoration was seen immediately after the treatment, after three months in $90 \%$ of patients, and after six months in $97 \%$ of the patients and after one year.

On a Global Aesthetic Improvement Scale from 1 to 5 (worsening, no change, improved, much improved, very much improved, respectively), improvement in the overall appearance of the face was scored 2.7 after three months and 2.0 after six and twelve months by the patients.

The blinded assessment of the photographs rated the improvement after three months of the treatment as improved in 9 patients, much improved in 18 patients and very much improved in 3 patients, with an average GAIS 1.9. Results improved after six months and remains stable for one year. (Table 1)

Results are shown in Figure 3.

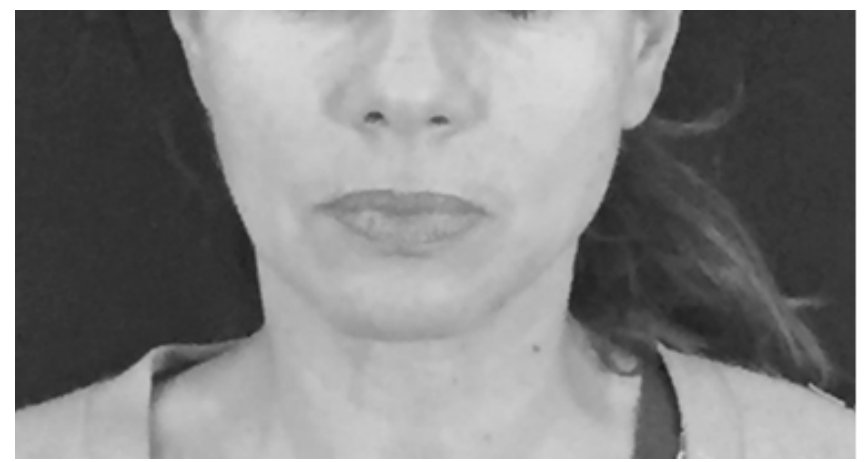




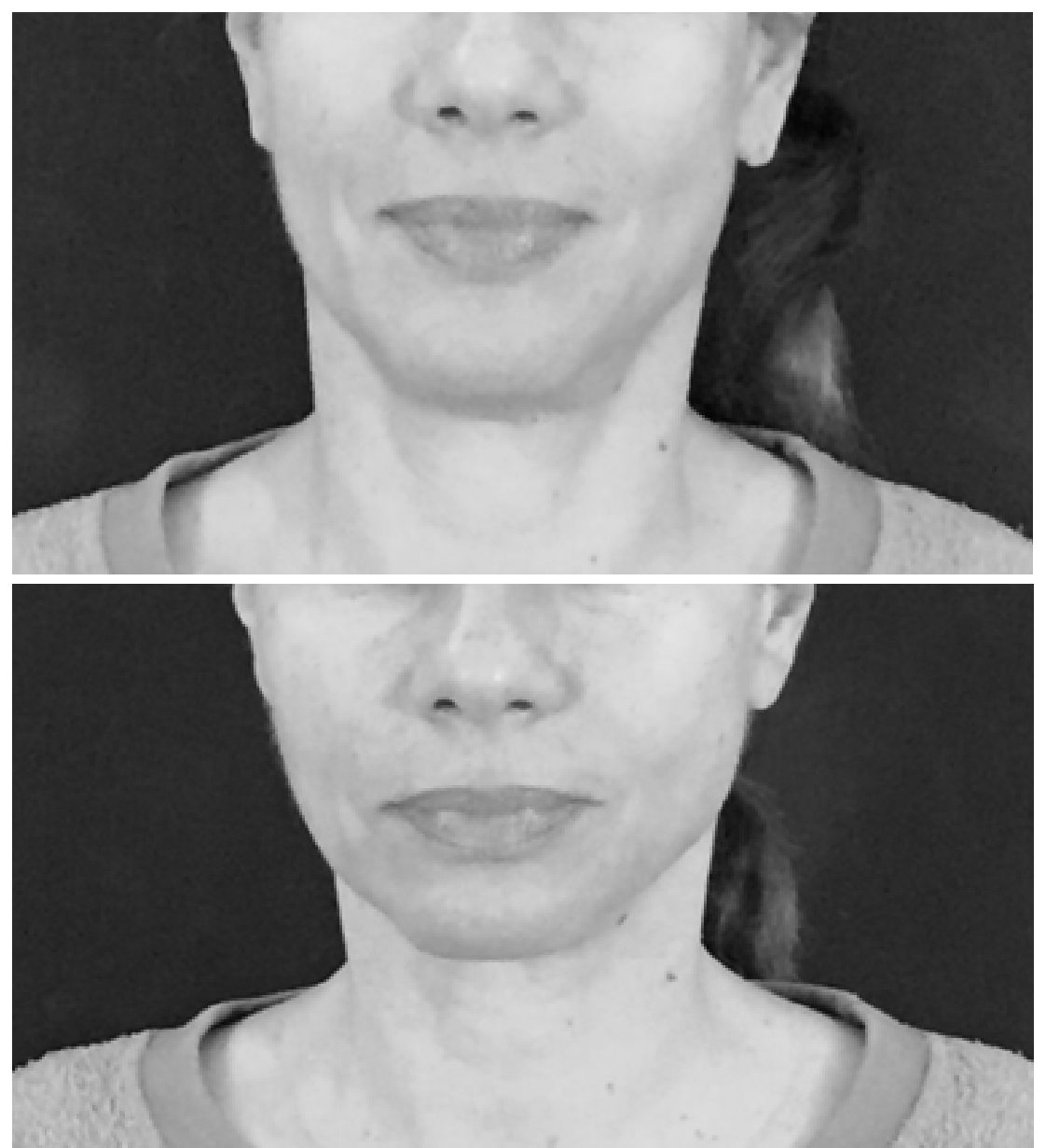

Figure 3 Results improved after six months and remains stable for one year.

Table I Results improved after six months and remains stable for one year

\begin{tabular}{|c|c|c|c|c|c|}
\hline & Pretreatment & I week & Post 3 months & Post 6 months & Post I 2 months \\
\hline $\begin{array}{l}\text { Global Facial } \\
\text { Assessment }\end{array}$ & $\begin{array}{l}16 \text { pcs } 2 \text { grade } \\
10 \text { pcs } 3 \text { grade } \\
4 \text { pcs } 4 \text { grade } \\
\text { Average } 2.6\end{array}$ & unchanged & $\begin{array}{l}18 \text { pcs I degree } \\
9 \text { pcs } 2 \text { grade } \\
3 \text { pcs } 3 \text { grade } \\
\text { Average I.35 }\end{array}$ & $\begin{array}{l}23 \text { pcs I grade } \\
6 \text { pcs } 2 \text { grade } \\
\text { I pc } 3 \text { grade } \\
\text { Average I. } 26\end{array}$ & $\begin{array}{l}\text { I8 pcs I degree } \\
8 \text { pcs } 2 \text { grade } \\
4 \text { pcs } 3 \text { grade } \\
\text { Average } 1.53\end{array}$ \\
\hline Adverse events & & $\begin{array}{l}2 \text { pcs with mild } \\
\text { bruises at the } \\
\text { cannula entry site }\end{array}$ & nobody & nobody & \\
\hline Hinderer's Lines & $\begin{array}{l}30 \text { pcs ptosis of } \\
\text { malar prominence } \\
100 \%\end{array}$ & unchanged & $\begin{array}{l}27 \text { out of } 30 \\
\text { improvement of } \\
\text { malar prominence } \\
10 \%\end{array}$ & $\begin{array}{l}29 \text { out of } 30 \\
\text { improvement of } \\
\text { malar prominence } \\
3.3 \%\end{array}$ & $\begin{array}{l}27 \text { su } 30 \\
\text { miglioramento della } \\
\text { prominenza malare } \\
10 \%\end{array}$ \\
\hline $\begin{array}{l}\text { Self-assessment using } \\
\text { GAIS (Global Aesthetic } \\
\text { Improvement Scale) }\end{array}$ & & unchanged & $\begin{array}{l}9 \text { pcs } 2 \text { (much } \\
\text { improved) } \\
20 \text { pcs } 3 \text { (improved) } \\
\text { I pc } 4 \text { (no change) } \\
\text { Average } 2,7\end{array}$ & $\begin{array}{l}4 \text { pcs I (very much } \\
\text { improved) } \\
23 \text { pcs } 2 \\
2 \text { pcs } 3 \\
\text { I pc } 4 \\
\text { Average } 2,0\end{array}$ & $\begin{array}{l}3 \text { pcs I (very much } \\
\text { improved) } \\
24 \text { pcs } 2 \\
\text { I pcs } 3 \\
2 \text { pcs } 4 \\
\text { Average } 2,06\end{array}$ \\
\hline $\begin{array}{l}\text { Specialist assessment } \\
\text { outside the procedure } \\
\text { via GAIS }\end{array}$ & & unchanged & $\begin{array}{l}3 \text { pcs I } \\
18 \text { pcs } 2 \\
9 \text { pcs } 3 \\
\text { Average } 1,9\end{array}$ & $\begin{array}{l}6 \text { pcs I } \\
20 \text { pcs } 2 \\
4 \text { pcs } 3 \\
\text { Average } 1,9\end{array}$ & $\begin{array}{l}6 \text { pcs } 1 \\
20 \text { pcs } 2 \\
4 \text { pcs } 3 \\
\text { Average } 1,9\end{array}$ \\
\hline
\end{tabular}




\section{Discussion}

The use of radiofrequency currents in aesthetic medicine has been consolidated for some time. These technologies have shown considerable use in correcting facial laxity and consequently improving the nasolabial furrows and repositioning the prominence of the cheekbone. ${ }^{9-16}$

The present trial included Caucasian patients with Fitzpatrick skin types I-III. We observed a marked improvement in skin laxity and fine wrinkling. Adverse effects were not noted. In this trial, we limited the application to two treatment only.

Endodermal radiofrequency is certainly applicable to any age and patient with moderate to severe facial laxity. The results are certainly excellent in younger people for an active response by a more biologically responsive subcutaneous. Radio frequency cannot be considered a substitute for surgical treatment but can postpone it or perform a less aggressive intervention. ${ }^{17-19}$

Surely this study has limitations, given the small number of patients enrolled and the difficulty of having an objective measure of skin laxity. Multicenter studies and more detailed measurements of results would be useful.

Given these assumptions, the device appears to be a valid tool with high levels of patient satisfaction.

\section{Conflicts of interest}

The authors declare no conflict of interest.

\section{Acknowledgments}

None.

\section{Funding}

None.

\section{References}

1. Wasserman D, Avram MA. Pathophysiology of skin laxity and cellulite. In: Katz BE, Sadick NS, Dover JS, Alam M, editors. Body Contouring Procedures in Cosmetic Dermatology. USA: Saunders Elsevier. 2010. pp. 25-30.

2. Sadick NS, Makino Y. Selective electro-thermolysis in aesthetic medicine: A review. Lasers Surg Med. 2004;34(2):91-97.

3. Zelickson BD, Kist D, Bernstein E, et al. Histological and ultrastructural evaluation of the effects of a radiofrequency-based nonablative dermal remodeling device: A pilot study. Arch Dermatol. 2004;140(2):204-209.

4. Goldman A, Shavelzon D, Blugerman G. Laser lipolysis: Liposuction using Nd:YAG laser. Rev Soc Brasil Chir Plast. 2002;17:17-21.
5. Goldman A. Submental Nd:YAG laser-assisted liposuction. Lasers Surg Med. 2006;38(3):181-184.

6. Arnoczkay SP, Aksan A. Thermal modification of connective tissues: Basic science considerations and clinical implications. J Am AcadOrthop Surg. 2000;8(5):305-313.

7. Dierickx CC. The role of deep heating for non invasive skin rejuvenation. Laser Surg Med. 2006;38(9):799-807.

8. Homoth $\mathrm{J}$, Wenderoth $\mathrm{M}$, Druga $\mathrm{T}$, et al. Electronic transport on the nanoscale: Ballistic transmission and Ohm's law. Nano Lett. 2009;9(4):1588-1592.

9. Hsu TS, Kaminer MS. The use of nonablative radiofrequency technology to tighten the lower face and neck. Semin Cutan Med Surg. 2003;22(2):115123 .

10. Fitzpatrick R, Geronemus R, Goldberg D, et al. Multicenter study of noninvasive radiofrequency for periorbital tissue tightening. Lasers Surg Med. 2003;33(4):232-342.

11. Alster TS, Tanzi E. Improvement of neck and cheek laxity with a nonablative radiofrequency device: A lifting experience. Dermatol Surg. 2004;30:503-507.

12. Nahm WK, Su TT, Rotunda AM, et al. Objective changes in brow position, superior palpebral crease, peak angle of the eyebrow and jowl surface area after volumetric radiofrequency treatments to half of the face. Dermatol Surg. 2004;30(6):922-928.

13. Fritz M, Counters JT, Zelickson BD. Radiofrequency treatment for middle and lower face laxity. Arch Facial Plast Surg. 2004;6(6):370-373.

14. Koch RJ. Radiofrequency nonablative tissue tightening. Facial Plast Surg Clin North Am. 2004;12(3):339-346.

15. Weiss RA, Weiss MA, Munavalli G, et al. Monopolar radiofrequency facial tightening: A retrospective analysis of efficacy and safety in over 600 treatments. J Drugs Dermatol. 2006;5(8):707-712.

16. Alexiades-Armenakas M, Rosenberg D, Renton B, et al. Blinded, randomized, quantitative grading comparison of minimally invasive, fractional radiofrequency and surgical face-lift to treat skin laxity. Arch Dermatol. 2010; 146(4):396-405.

17. Ascher B. Sydney Coleman, Tina Alster, et al. Full scope of effect of facial lipoatrophy: a framework of disease understanding. Dermatol Surg. 2006;32(8):1058-1069.

18. Ruiz-Esparza J. Noninvasive lower eyelid blepharoplasty: A new technique using nonablative radiofrequency on periorbital skin. Dermatol Surg. 2004;30(2):125-129.

19. Finzi E, Spangler A. Multipass vector (mpave) technique with nonablative radiofrequency to treat facial and neck laxity. Dermatol Surg. 2005;31(8):916-922. 